\title{
The influence of substrate location and deposition time on $\mathrm{ZnO}$ nanostructures
}

\author{
Khalifa Al-Azri", Roslan Md Nor, Majid.S.Al-Ruqeishi and Y. M. Amin \\ Department of physics, Faculty of Science, University Malaya50603 Kuala Lumpur, Malaysia \\ *ay3579@yahoo.com Tel:+603-79674206 Fax: :+603-79674146(Corresponding author). Received on $18^{\text {th }}$ \\ June 2009, accepted in revised form $20^{\text {th }}$ July 2010.
}

\begin{abstract}
A study on the formation of $\mathrm{ZnO}$ nanostructures using the carbothermal evaporation method without catalyst and at atmospheric argon pressure has been conducted. The effects of the position of the substrates to the source and deposition time were investigated. The results of these parametric studies based on field-emission scanning electron microscopy (FESEM), Energy dispersive X-ray spectroscopy (EDX) spectrum and X-ray diffraction (XRD) analyses support the reduction-evaporation model for $\mathrm{ZnO}$ nanostructures formation using carbothermal evaporation.
\end{abstract}

(Keywords: $\mathrm{ZnO}$; nanostructures; carbothermal evaporation)

\section{INTRODUCTION}

Zinc oxide $(\mathrm{ZnO})$ has attracted extensive research efforts because it exhibits many unique interesting properties, including anisotropy in crystal structure, nonstoichiometric defect structures, a direct wide band gap $(3.37 \mathrm{eV})$ at room temperature and large exciton binding energy of $60 \mathrm{meV}$ [1].

Based on the unique properties of $\mathrm{ZnO}$ nanostructures, there are many novel applications have been appeared. For example, $\mathrm{ZnO}$ wires have been applied to construct Schottky diodes [2], field effect transistors (FET) [3] and light emitting diodes (LEDs) [4]. In recent years, number of different morphologies and fabrication methods for $\mathrm{ZnO}$ nanostructures were demonstrated.

Up to now, various $\mathrm{ZnO}$ nanostructures including nanowires [5], nanorods [6], nanotubes [7], nanoribbons [8], nanobelts [9] have been reported. Typically, good quality $\mathrm{ZnO}$ materials have been reported by different methods, including organic chemical vapor-phase epitaxy [10], carbothermal reactions [11], infrared irradiation, thermal evaporation and thermal decomposition [12,13] and laser assisted vaporliquid-solid growth [14].

Among these, carbothermal reactions method give many advantages such as simpliaty, economical and suitable for high yield production of $\mathrm{ZnO}$ nanostructures. However, some problems have been reported [15] in synthesized $\mathrm{ZnO}$ nanostructures including metal contamination during the growth process that affect negatively the properties of $\mathrm{ZnO}$ nanostructures. Thus, researchers have developed some processes to synthesize $\mathrm{ZnO}$ nanostructures without any catalysts $[16,17]$.

In addition, $\mathrm{ZnO}$ nanostructures exhibit a wide range of electrical and optical properties that depend sensitively on both shape and size, and both of fundamental and technological interest. For that reason, understanding the relationship between the effects of different growth parameters and the growth mechanism is very important for controlling the size and the shape of $\mathrm{ZnO}$ nanostructures.

In this paper, we reported a chemical vapor transport and condensation (CVTC) route to synthesize $\mathrm{ZnO}$ nanostructures without catalyst and at atmospheric pressure. In addition, the effects of experiment parameters such as the substrate locations and deposition time on the mechanism growth have been investigated.

\section{Experimental Setup}

In the typical growth process, n-type Si (100) wafers were used as substrates for growth of $\mathrm{ZnO}$ nanostructures. Before the growth process, the silicon substrates were dipped in sonicating bath of acetone for 15 minutes and rinsed with deionized water.

The experimental system consisted of a horizontal tube furnace $(110 \mathrm{~cm}$ long), a temperature controller, gas supply and control system. The horizontal tube was opened from one side to the air and other end linked to a gas supply and flow control system.

The source material was mixtures of high-purity $\mathrm{ZnO}$ (Sigma Aldrich 99.9\%) and carbon powders (Sigma Aldrich 99.95\%) with 1:1 molar ratio. A 
porcelain boat ( $2 \mathrm{~cm}$ diameter, $8 \mathrm{~cm}$ long) with the $\mathrm{ZnO} / \mathrm{C}$ mixture was placed into the horizontal tube and pushed to the center of the furnace.

Silicon substrate pieces were placed at different locations range from 6 to $19 \mathrm{~cm}$ downstream from the center. Deposition process was conducted at $1100{ }^{\circ} \mathrm{C}$ furnace temperature and the $\operatorname{Ar}(99.9 \%)$ flow rate was set at 40 standard cubic centimeters per minute (s.c.c.m.) for 15,30 , 45 and 60 minutes.

Due to the temperature gradient downstream, the temperature of substrate region was less than the source temperature. The quartz tube was drawn out from the furnace and cooled down to room temperature in the air. White and gray colors products were formed on the surface of the silicon wafers.

The as-grown $\mathrm{ZnO}$ nanostructures were characterized by field emission gun scanning electron microscopy (FESEM) (Quanta200F), Energy dispersive X-ray spectroscopy (EDX) spectrum (Oxford Inst), X-ray diffraction (XRD) (Siemens D-5000 diffractometer by using coppermonochromatized $\mathrm{Cu} \quad \mathrm{K} \alpha 1$ radiation $(\lambda=1.540598 \AA)$ under the accelerating voltage of $40 \mathrm{kV}$ and the current of $40 \mathrm{~mA}$.

\section{RESULTS AND DISCUSSIONS}

\section{Effect of the location of the Si substrate}

Typical FESEM images of the $\mathrm{ZnO}$ products obtained from the study of the substrates location variation are shown in figure 1. In figure 1(a), a complete film of $\mathrm{ZnO}$ was formed with particles of a few micrometers in size for the sample located at $6 \mathrm{~cm}$ away from the center. Figure 2 shows the corresponding (EDX) spectra for all the studied samples. Figure 2 (a) shows that the atomic $\%$ of $\mathrm{Zn}$ element was very small compared to silicon.

This indicates that at short distance from the source, the substrate has higher temperature than the boiling temperature of the $\mathrm{Zn}\left(907^{\circ} \mathrm{C}\right)$ and this leads to re-evaporated of $\mathrm{Zn}$ atoms from the substrate without being oxidized. At $11 \mathrm{~cm}$ away from the center aligned $\mathrm{ZnO}$ nanowires were formed on silicon substrate as illustrated in figure 1(b).

The average diameter of these nanowires was about $50 \mathrm{~nm}$ to $200 \mathrm{~nm}$ and the length was 4$8 \mu \mathrm{m}$. The EDX spectrum in figure 2(b) demonstrates that the percentage of $\mathrm{Zn}$ and oxygen were increased compared to silicon.
Figure 1(c) shows irregular shape of $\mathrm{ZnO}$ nanostructures with non-aligned nanowires were formed in large quantity for the sample at $15 \mathrm{~cm}$ far from the center.

The corresponding EDX result in figure 2(c) showed significant increase in the $\mathrm{Zn}$ and $\mathrm{O}$ peaks relative to the silicon peak. For the silicon substrate which was located $19 \mathrm{~cm}$ away from the center, microstructures in the form of disks were obtained as shown in figure 1(d). The corresponding EDX result as it is shown in figure 2(d), no oxygen peak was observed and the microstructures disks were only contented of $\mathrm{Zn}$.

This is a direct evidence of the carbothermal mechanism of the $\mathrm{ZnO}$ nanostructures formation where reduction of $\mathrm{ZnO}$ occurred in $\mathrm{ZnO} / \mathrm{C}$ mixture at elevated temperatures to produce $\mathrm{Zn}$, which evaporated and redeposit on the substrates. In other words, $\mathrm{ZnO}$ nanostructures were formed upon silicon substrates via the oxidation of the deposit Zn.

Figure 3 shows the XRD patterns of the samples grown on $\mathrm{Si}\left(\begin{array}{lll}1 & 0 & 0\end{array}\right)$ substrates at different locations from the center of the furnace. The strong intensity and narrow width of $\mathrm{ZnO}$ diffraction peaks indicate that the resulting products were of high crystallinity. On one hand, no diffraction peaks from metallic $\mathrm{Zn}$ or other impurities were detected in the samples located at $11 \mathrm{~cm}$ and $15 \mathrm{~cm}$ besides $\mathrm{ZnO}$ peaks.

Thus, the XRD diffraction peaks can be assigned to (100), (002), (101), (102), (103) and (112) standard hexagonal wurtzite structure of $\mathrm{ZnO}$ with cell parameter of $\mathrm{a}=\mathrm{b}=3.249 \AA$, and $\mathrm{c}=$ $5.206 \AA$ [18]. On the other hand, strong $\mathrm{Zn}$ (0 01 1), (101), and (102) diffraction peaks were observed at $19 \mathrm{~cm}$ sample location which, is indicated that the prepared sample was mainly composed of a great number of $\mathrm{Zn}$ with little oxidation. Whereas, very weak $\mathrm{ZnO}$ of (100), (002), and (101) peaks were observed in the sample located at $6 \mathrm{~cm}$.

Moreover, wide width of $\mathrm{ZnO}$ diffraction peak at $2 \theta=56.59^{\circ}$ indicates that the resulting products had very small size of crystalline and the resulting products were amorphous. It is noticeable that the $\left(\begin{array}{lll}0 & 0 & 2\end{array}\right)$ peak (at $\left.34.3^{\circ}\right)$ is overwhelming, revealing a preferred orientation of the nanowires grown on silicon substrates that was at $11 \mathrm{~cm}$ location and hence, reveals align nanowires as observed in the FESEM image. As a result, different $\mathrm{ZnO}$ morphologies were formed at different substrate locations. 

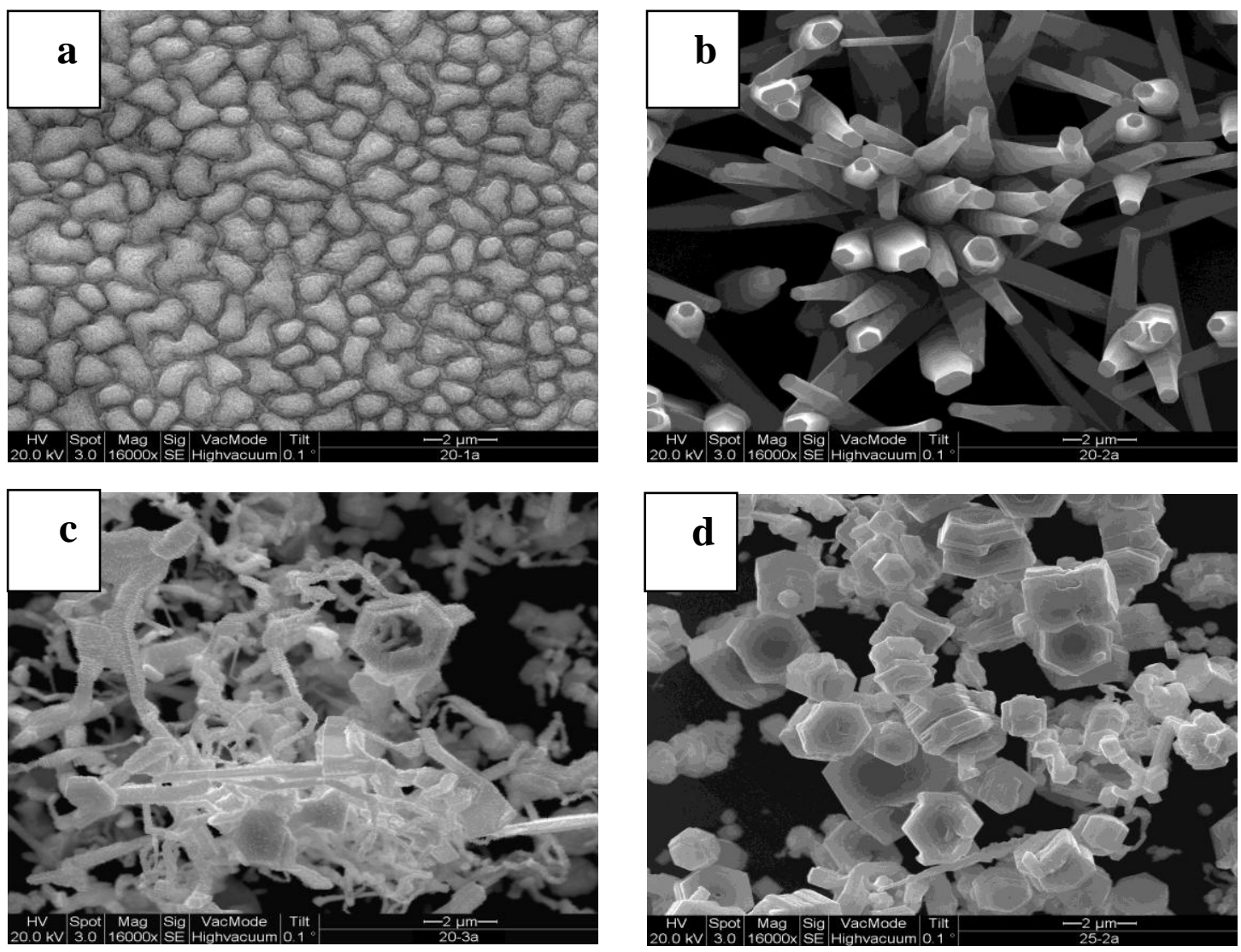

Figure 1: displays FESEM images of $\mathrm{ZnO}$ nanostructures grown on silicon substrates located at (a) $6 \mathrm{~cm}$ (b) $11 \mathrm{~cm},(\mathrm{c}) 15 \mathrm{~cm}$ and $(\mathrm{d}) 19 \mathrm{~cm}$ from the center.
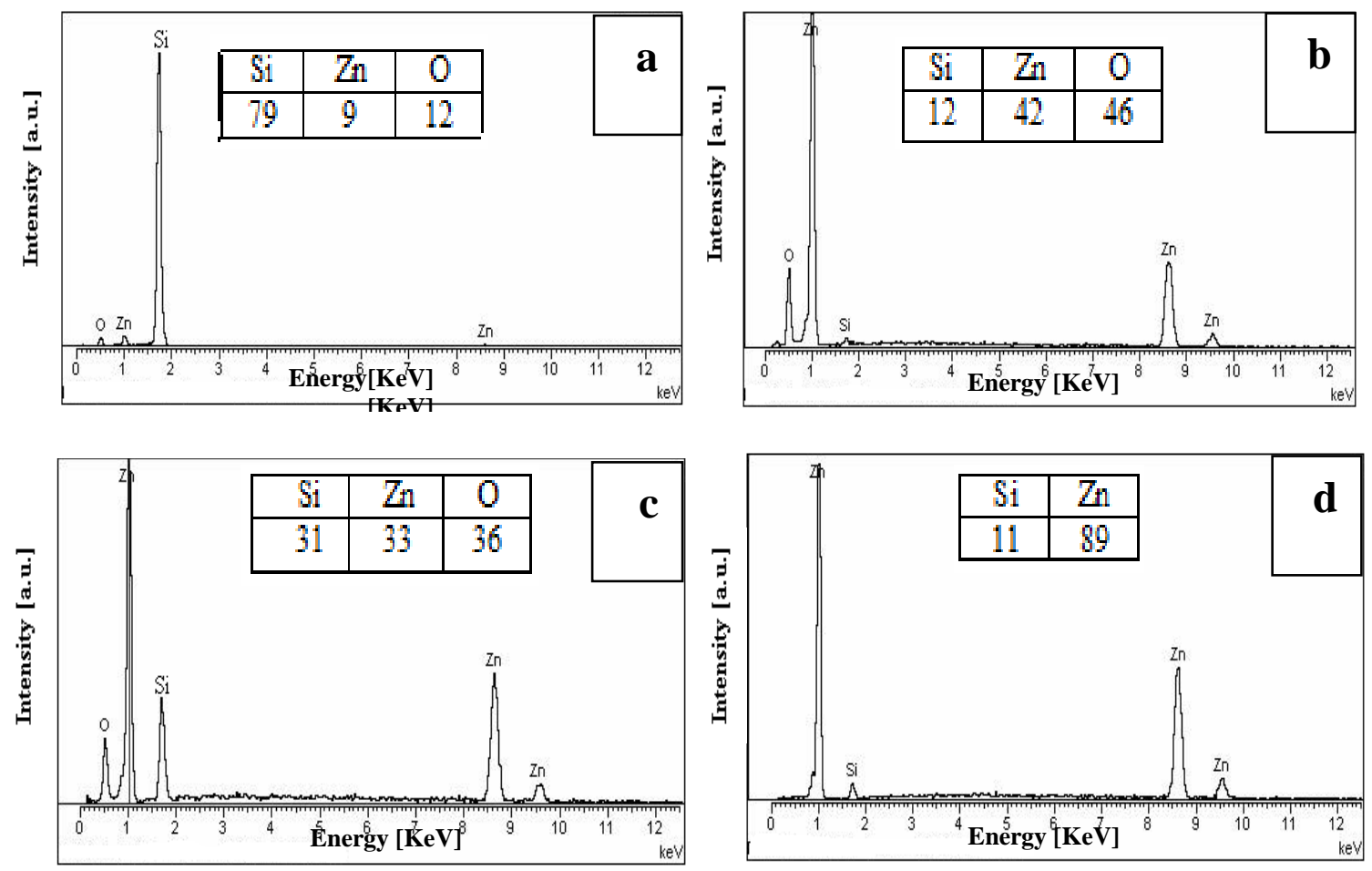

Figure 2: shows Figure 2: shows EDX spectra of $\mathrm{ZnO}$ nanostructures grown on silicon substrates located at (a) $6 \mathrm{~cm}$ (b) $11 \mathrm{~cm}$ (c) $15 \mathrm{~cm}$ (d) $19 \mathrm{~cm}$ away from the center. 


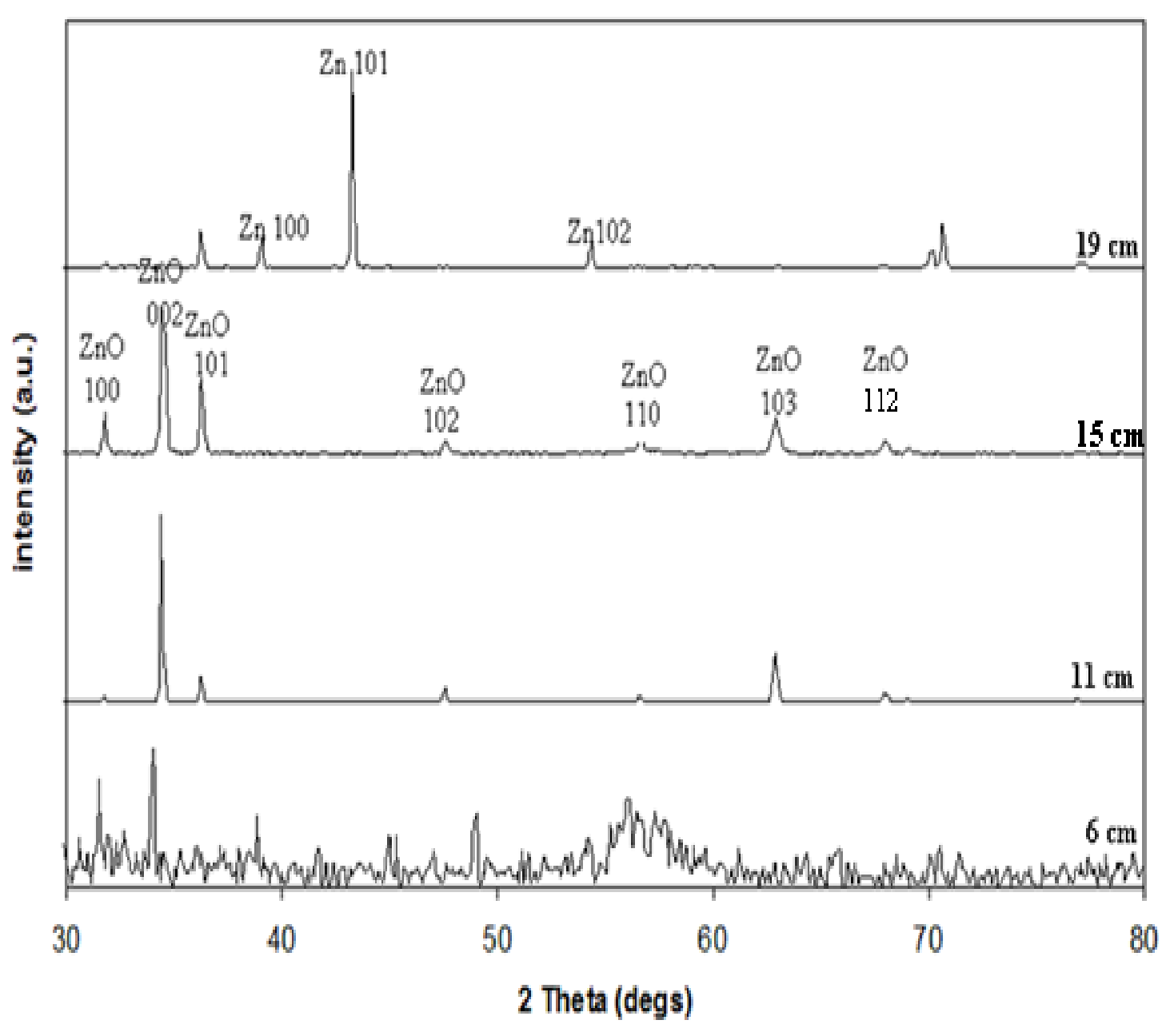

Figure 3: shows the XRD patterns of $\mathrm{ZnO}$ nanostructures deposited on the $\mathrm{Si}$ (100) substrates at different locations from the center.

\section{Effect of deposition time}

Figure 4 implies FESEM images of $\mathrm{ZnO}$ nanostructures grown on silicon substrates at different deposition times. Obviously, the growth density of synthesized $\mathrm{ZnO}$ nanostructures increases with increasing the deposition time. Figures 5 (a) and (b) display corresponding EDX spectra of $15 \mathrm{~min}$ and $60 \mathrm{~min}$ grown samples.

According to EDX results, there is no silicon peak was detected on 60 min deposition time, whereas silicon peak was observed at $15 \mathrm{~min}$ deposited substrate. This result gives a good evidance to the enhancement of the growth yield of $\mathrm{ZnO}$ nanostructures as the depostion time is increased.

When the growth time increased to $60 \mathrm{~min}$, the silicon substrate was all covered with nanostructures as it shown in figure $4(\mathrm{~d})$. It is interesting to note that all the FESEM images display nanotetrapod structures.

In addition, shorter nanotetrapods with large diameters were formed as deposition time increased. In other words, shorter $\mathrm{ZnO}$ nanotetrapods with larger diameter are obtained at $60 \mathrm{~min}$ deposition time. The longest nanotertrapods legs were obtained in $15 \mathrm{~min}$ deposition time with $700 \mathrm{~nm}$ tall and $30 \mathrm{~nm}$ width where the largest nanotetrapods diameter which equal to $200 \mathrm{~nm}$ with $400 \mathrm{~nm}$ length was formed at $60 \mathrm{~min}$ deposition time.

It is worth to point out that when the deposition time increased from $45 \mathrm{~min}$ to $60 \mathrm{~min}$, $\mathrm{ZnO}$ nanostructures changed from nanotertrapods to sheets form. Hence, the deposition time play a key role in control the dimensions of $\mathrm{ZnO}$ nanostructures. 

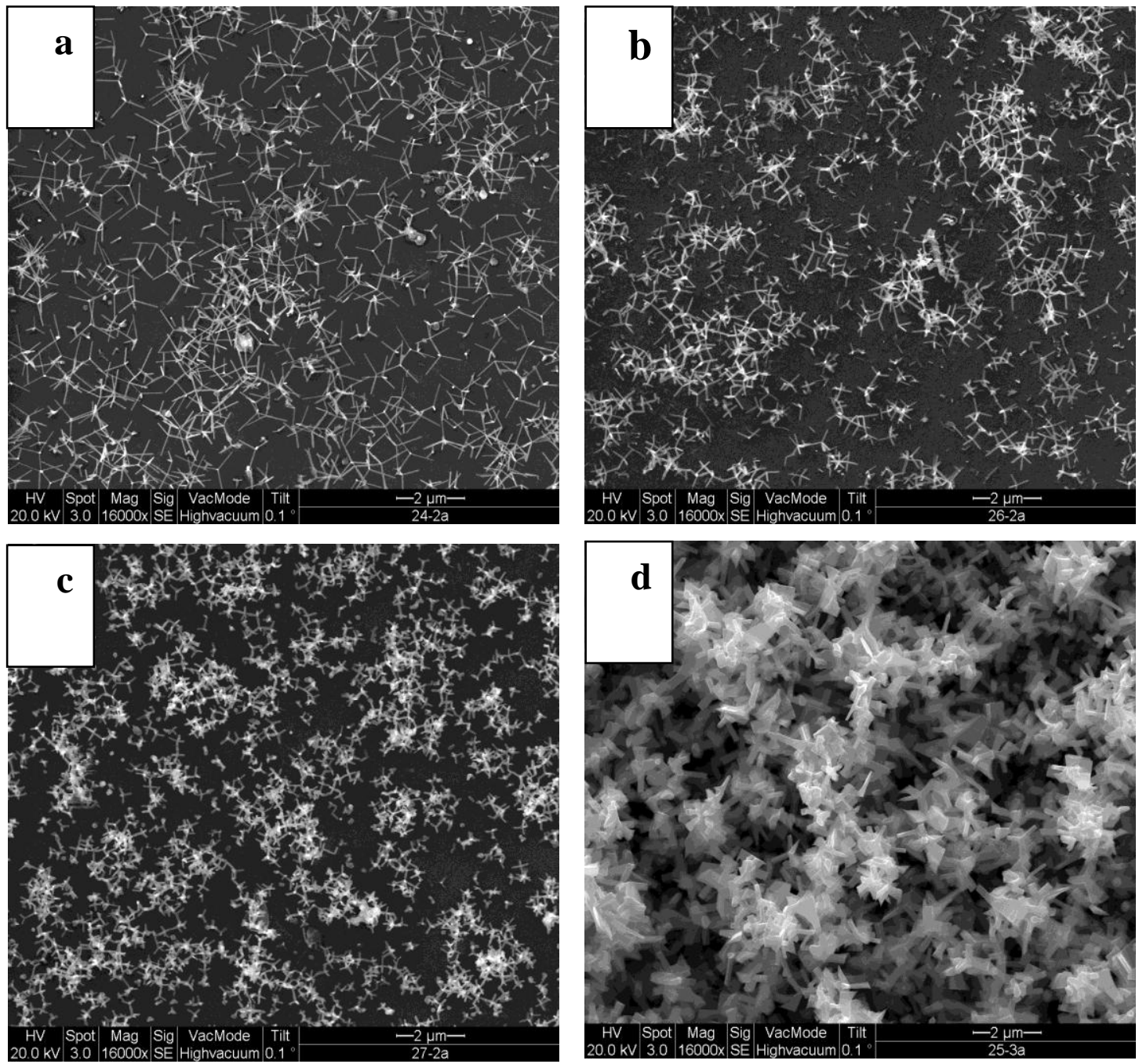

Figure 4: displays FESEM images of $\mathrm{ZnO}$ nanostructures formed upon silicon substrates deposited at (a)

$15 \mathrm{~min}$ (b) 30min, (c) $45 \mathrm{~min}$ and (d) 60min deposition time.
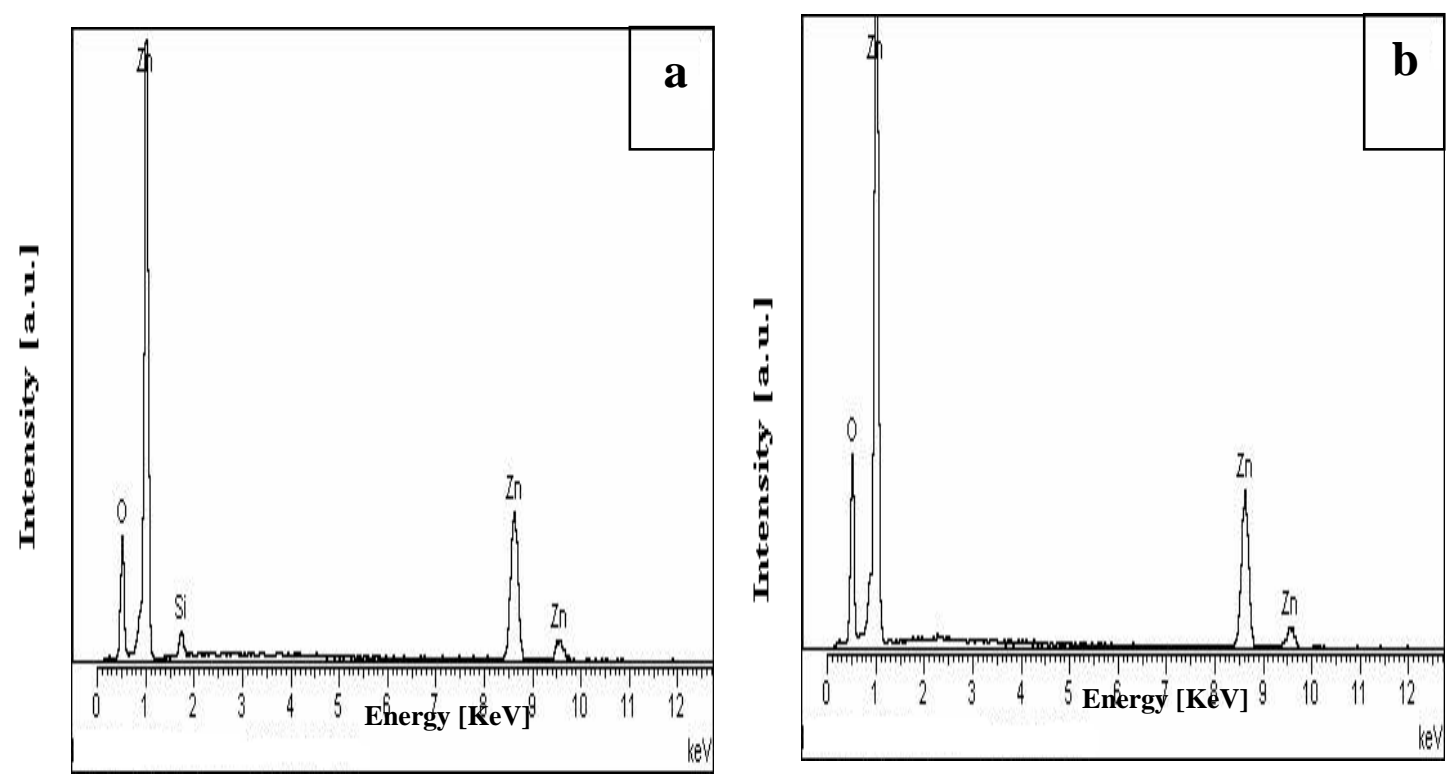

Figure 5: shows EDX spectra of $\mathrm{ZnO}$ nanostructures grown at (a) $15 \mathrm{~min}$ (b) 60 min deposition time. 
Figure 6 shows typical XRD patterns of the assynthesized $\mathrm{ZnO}$ nanostructures at different deposition time. No diffraction peaks of metallic $\mathrm{Zn}$ or other impurities can be observed besides $\mathrm{ZnO}$ peaks for all the grown samples. Obviously, XRD spectra reveal that as deposition time increased a high density of $\mathrm{ZnO}$ products formed. In addition, (100), (002) and (101) peaks have been observed and they have almost the same intensities from $15 \mathrm{~min}$ to $45 \mathrm{~min}$ deposition time. In contrast, the highest intensity of (002) peak, at 60 min deposition time, shows that those nanostructures are grown along the c-axis direction that is normal to the substrates. As a result, the intensity of the $\mathrm{ZnO}$ (002) peak significantly enhances with increasing deposition time to $60 \mathrm{~min}$.

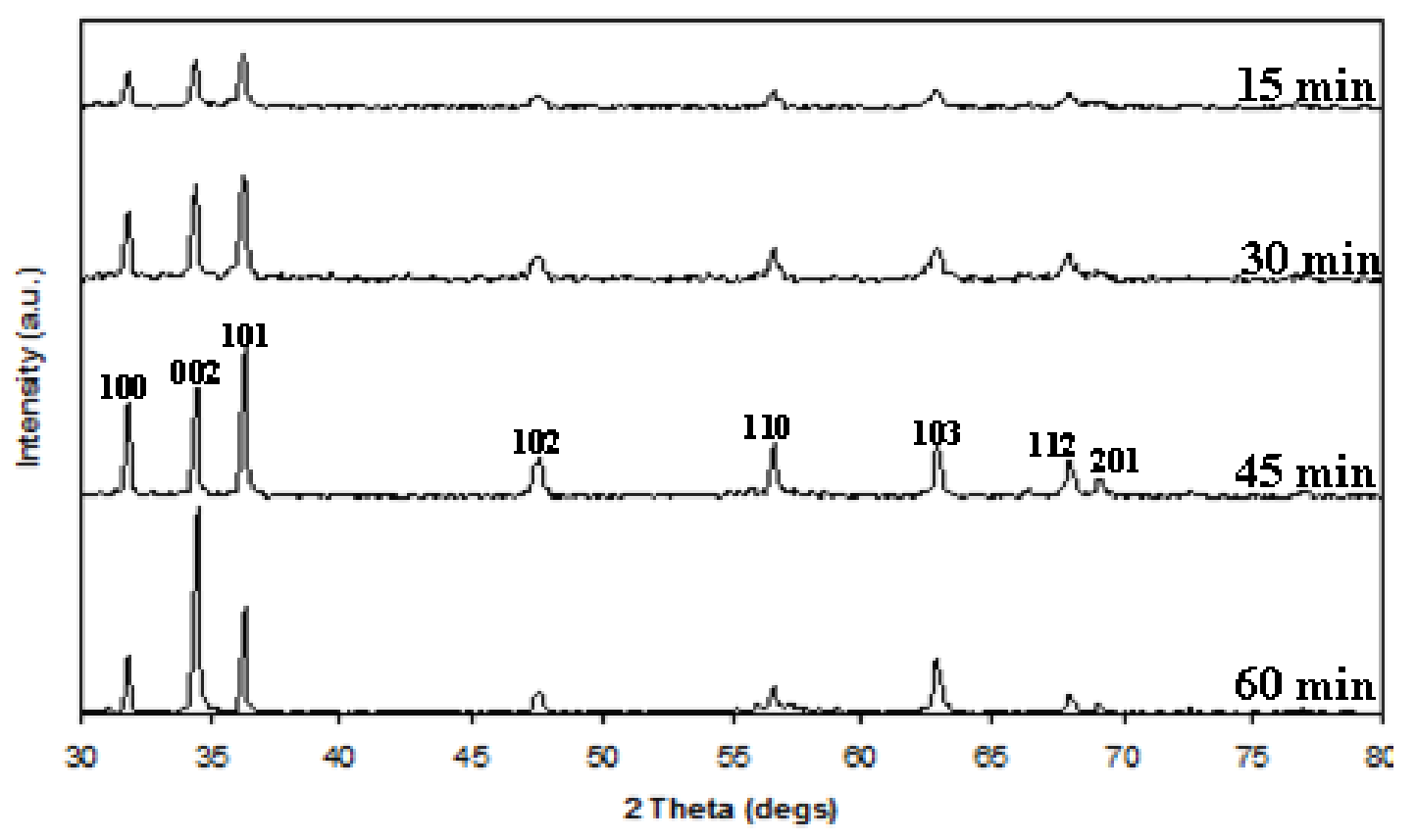

Figure 6: shows typical XRD patterns of the as-synthesized $\mathrm{ZnO}$ nanostructures at different deposition time.

\section{Mechanism of $\mathrm{ZnO}$ nanostructures growth}

The growth of $\mathrm{ZnO}$ nanostructures without catalyst has been demonstrated by various methods. In this work, the growth mechanism can attribute to self-catalytic vapor-liquid-solid (VLS) mechanism [4], whereas $\mathrm{Zn}$ and $\mathrm{Zn}$ suboxides functioned as self-catalysts.

To facilitate the production of $\mathrm{ZnO}$ nanostructures in simple evaporation and at atmospheric pressure, the growth reduction was utilized to decompose high-melting-point $1,975^{\circ} \mathrm{C}$ of $\mathrm{ZnO}$ at lower-melting point. This happened when, $\mathrm{ZnO}$ powder is mixed with graphite powders to form $\mathrm{Zn}$ and $\mathrm{CO}$ gas as illustrated in Eq. (1).

$\mathrm{ZnO}($ solid $)+\mathrm{C}($ solid $) \rightarrow \mathrm{Zn}($ gas $)+\mathrm{CO}$

Then, CO gas worked as reduction agent with $\mathrm{ZnO}$ powder to form more of $\mathrm{Zn}$ vapor and $\mathrm{CO} 2$ gas as shown in Eq. (2).

$\mathrm{ZnO}($ solid $)+\mathrm{CO}($ gas $) \rightarrow \mathrm{Zn}($ gas $)+\mathrm{CO} 2----(2)$
$\mathrm{Zn}$ and $\mathrm{CO} 2$ vapors were then transported or diffused to a low temperature region (downstream of carrier gas flow), which they reacted to form $\mathrm{ZnO} / \mathrm{ZnO}_{\mathrm{X}}$ liquid droplets and $\mathrm{CO}$ gas which depart the tube as shown in Eq. (3).

$\mathrm{Zn}($ gas $)+\mathrm{CO}_{2}($ gas $) \rightarrow \mathrm{ZnO}($ liquid $)+\mathrm{CO}($ gas $)-$ $-(3)$

Moreover, a part of the $\mathrm{Zn}$ vapor will condense on the substrate to form liquid droplets, which are the preferred sites to absorb $\mathrm{ZnO}$ or $\mathrm{ZnO}_{\mathrm{X}}$ vapor species.

It means that the $\mathrm{Zn} / \mathrm{ZnO}$ or $\mathrm{Zn} / \mathrm{ZnO}_{\mathrm{X}}$ liquid droplets functioned as a nucleation site for subsequent $\mathrm{Zn}$ and $\mathrm{Zn}$-suboxides which are in vapor phase and absorb them until the droplet became supersaturated and results in $\mathrm{ZnO}$ segregation and nanostructures growth. On one hand, the vapor pressure of $\mathrm{Zn}, \mathrm{ZnOx}$ and $\mathrm{CO} / \mathrm{CO} 2$ was gradually decreased from the powder source location to the open side of the quartz tube. For that reason, we observed that growth yield was very low. 
In addition, we believed that the $\mathrm{Si}$ substrate at $19 \mathrm{~cm}$ away from the source had low local temperature and any $\mathrm{Zn}$ vapor arrived to the substrate, it will solidified immediately and hence, $\mathrm{Zn}$ has only been obtained on Si (100).

In contrast, at the high temperature $\mathrm{Si}$ substrate at $6 \mathrm{~cm}$ away from the source, the $\mathrm{Zn} / \mathrm{ZnOx}$ vapor has enough energy to keep its vapor phase and only a few particles can deposit on the edge of the growing $\mathrm{ZnO}$ grains resulting in $\mathrm{ZnO}$ film. On the other hand, as deposition time increased more vapors carried by the flow gas towards the substrate surface and hence, more dense $\mathrm{ZnO}$ nanostructures formed upon the substrate surface.

\section{CONCLUSION}

The dependence of $\mathrm{ZnO}$ nanostructures on the substrate position to the $\mathrm{ZnO} / \mathrm{C}$ source confirmed the reduction-evaporation model of $\mathrm{ZnO}$ formation using carbothermal technique. There seem to be a define window of distances for $\mathrm{ZnO}$ nanostructures to be formed. For our system, the best distance was at $11 \mathrm{~cm}$.

The closest distance studied yielded $\mathrm{ZnO}$ film and the furthest distance yielded only $\mathrm{Zn}$. It was discovered that, density of $\mathrm{ZnO}$ increased with increasing the deposition time, which may be due the increase in the supply of $\mathrm{Zn}, \mathrm{ZnOx}$ and $\mathrm{CO} / \mathrm{CO} 2$ vapors delivered to substrate by the carrier gas.

In addition, by controlling such parameters aligned $\mathrm{ZnO}$ nanowires with different diameters and lengths can be grown reproducibly as we have obtained them at $11 \mathrm{~cm}$ substrate location. The average diameter of these nanowires is about $50 \mathrm{~nm}$ to $200 \mathrm{~nm}$ and the length is $4-8 \mu \mathrm{m}$.

\section{ACKNOWLEGEMENTS}

We would like to thank University Malaya (UM) for the financial support for this project (grant NO. PS303-2008C).

\section{REFERENCES}

1. Y.J. Xing, Z.H. Xi, Z.Q. Xue and X.D. Zhang. (2003). Optical properties of the $\mathrm{ZnO}$ nanotubes synthesized via vapor phase growth. Appl. Phys. Lett. 83: 1689-1691.

2. M. C. Newton, S.Firth and P.A.Warburton. (2006). ZnO tetrapod Schottky photodiodes. Appl. Phys. Lett. 89: 072104-072106.

3. J. Goldberger, D.J. Sirbuly, M. Law and P.D. Yang. (2005). ZnO nanowire transistors. J. Phys. Chem. B 109: 9-14.
4. J. M. Bao, M. A. Zimmler, F. Capasso, X. W. Wang and Z. F. Ren. (2006). Broadband ZnO single-nanowire light-emitting diode. Nano Lett. 6:1719-1722.

5. H.Y. Dang, J. Wang and S.S. Fan. (2003). The synthesis of metal oxide nanowires by directly heating metal samples in appropriate oxygen atmospheres. Nanotechnology 14: 738-741.

6. Y.W. Heo, V. Varadarajan, M. Kaufman, K. Kim, D.P. Norton, F. Ren and P.H. Fleming. (2002). Site-spectific growth of $\mathrm{ZnO}$ nanorods using catalysis-driven molecular-beam epitaxy. Appl. Phys. Lett. 81: 3046-3048.

7. J.-J. Wu, S.-C. Liu, C.-T. Wu, K.-h. Chen and L.-C. Chen. (2002). Heterostructures of $\mathrm{ZnO}-$ $\mathrm{Zn}$ coaxial nanocables and $\mathrm{ZnO}$ nanotubes. Appl. Phys. Lett. 81: 1312-1314.

8. B.D. Yao, Y.F. Chan and N. Wang. (2002). Formation of $\mathrm{ZnO}$ nanostructures by a simple way of thermal evaporation. Appl. Phys. Lett. 81: 757-759.

9. Y.B. Li, Y. Bando, T. Sato and K. Kurashima. (2002). ZnO nanobelts grown on Si substrate. Appl. Phys. Lett. 81: 144146.

10. L. L. Zhang, C.X. Guo, J.G. Chen and J.T. Hu. (2005). The synthesis of one-dimensional controllable $\mathrm{ZnO}$ microrods. Chin. Phys. 14: 586-591.

11. .J. Chen, X.W. Sun and C.X. Xu. (2004). Fabrication of zinc oxide nanostructures on gold-coated silicon substrate by thermal chemical reactions vapor transport deposition in air. Ceramics International 30: 1725-1729.

12. V. A. L. Roy, A. B. Djuriši, W. K. Chan, J. Gao, H. F. Lui and C. Surya. (2003). Luminescent and structural properties of $\mathrm{ZnO}$ nanorods prepared under different conditions. Appl. Phys. Lett. 83:141-143.

13. A.B. Djurišić, Y.H. Leung, W.C.H. Choy, K.W. Cheah and W.K. Chan. (2004). Visible photoluminescence in $\mathrm{ZnO}$ nanotetrapod and multipod structures. Appl. Phys. Lett. 84: 2635-2637.

14. Z.R. Dai, Z.W. Pan and Z.L. Wang. (2003). Novel nanostructures of functional oxides synthesized by thermal evaporation. Adv. Funct. Mater. 13: 9-24.

15. W. D. Yu, X. M. Li and X. D. Gao. (2004). Self-catalytic synthesis and photoluminescence 
of $\mathrm{ZnO}$ nanostructures on $\mathrm{ZnO}$ nanocrystal substrates. Appl. Phys. Lett. 84: 2658-2660.

16. Z. W. Pan, Z. R. Dai and Z. L. Wang. (2001). Nanobelts of semiconducting oxides. Science 291: 1947-1949.
17. Y. Dai, Y. Zhang, Q. K. Li and C. W. Nan (2002). Synthesis and optical properties of tetrapod-like zinc oxide nanorods. Nan. Chem. Phys. Lett. 358: 83-86.

18. JCPDS-International center for diffraction data, Card No. 03-0888. 